\title{
Physico-Chemical and Microbiological Quality Assessment of Supply Water around Dhaka City, Bangladesh
}

\author{
Md. Shamimuzzaman', Rashed Hasan Nayeem², Nargis Ara ${ }^{3}$, Md. Masuder Rahman", \\ Md. Iqbal Kabir Jahid"' Md. Nazmul Hasan ${ }^{5 *}$
}

\begin{abstract}
${ }^{1}$ Department of Microbiology, Faculty of Biological Science and Technology, Jessore University of Science and Technology, Jessore, Bangladesh

${ }^{2}$ Biotechnology and Genetic Engineering Discipline, School of Life Sciences, Khulna University, Khulna, Bangladesh

${ }^{3}$ Department of Pharmacy, University of Development Alternative, Dhaka, Bangladesh

${ }^{4}$ Department of Biotechnology and Genetic Engineering, Mawlana Bhashani Science and Technology University, Tangail, Bangladesh

${ }^{5}$ Department of Genetic Engineering and Biotechnology, Faculty of Biological Science and Technology, Jessore University of Science and Technology, Jessore, Bangladesh

Email: *mnhasan1978@gmail.com
\end{abstract}

How to cite this paper: Shamimuzzaman, M., Nayeem, R.H., Ara, N., Rahman, M.M., Jahid, M.I.K. and Hasan, M.N. (2019) Physico-Chemical and Microbiological Quality Assessment of Supply Water around Dhaka City, Bangladesh. Journal of Water Resource and Protection, 11, 280-295.

https://doi.org/10.4236/jwarp.2019.113016

Received: February 2, 2019

Accepted: March 8, 2019

Published: March 11, 2019

Copyright $\odot 2019$ by author(s) and Scientific Research Publishing Inc. This work is licensed under the Creative Commons Attribution International License (CC BY 4.0).

http://creativecommons.org/licenses/by/4.0/

\section{(c) (i) Open Access}

\begin{abstract}
Dhaka is one of the most densely-populated megacities in the world. Water supply problem is acute in this city, but the quality of drinking water has tremendous importance as potability. This study was aimed at comparing various physicochemical and microbiological parameters which are very much relevant for the drinking water quality of Dhaka city of Bangladesh. A total of 80 samples from 11 collection point of different places were collected over ten months. After that, the samples were examined by a different measuring device for physicochemical parameter testing. Considering physicochemical parameters, all water samples were within the limit for $\mathrm{pH}$. However, 53.75\% water had unsatisfactory for chlorine level. Total Dissolve Solid (TDS), hardness, iron, and alkalinity based unsatisfactory were $28.75 \%, 15.0 \%, 8.75 \%$, and $3.75 \%$ respectively. Five parameters had taken into consideration to measure the microbiological quality. The cultural and biochemical methods showed that 80 water samples have a different range of contamination. The total aerobic count was unsatisfactory for $53.75 \%$ samples. Sixty-one samples were found coliform contaminated that is $76.25 \%$ of the total samples and $58.75 \%$ sample was carried fecal substances. E. coli and Vibrio was unsatisfactory as $61.25 \%$ and $13.75 \%$ respectively. This study revealed that how much safe is supplied water of a municipal water supplier.
\end{abstract}




\section{Keywords}

Water Quality, Microbial Assay, Coliform, Fecal Coliform, Chlorination, Potability, Physicochemical Properties of Water, Pathogen

\section{Introduction}

Water scarcity is one of the most acute concerns in the current situation, and almost one-fifth of the world population has affected moreover 500 million people are approaching this situation [1]. Two main phenomena that cause water scarcity are increased freshwater use and depletion of a convenient source for freshwater [2]. Agriculture and urban are the two primary water users of total water consumption. Physical water would mainly satisfy the use of urban and environment [3]. Urban water management systems depend on their own lands their water source, so watersheds affect raw water quality and also the costs of water treatment [4]. To replenish the water scarcity, water reuse is the most effective persuade where environmental safety and quality is an issue [5]. More or less 1.8 billion people around the world are using fecally contaminated water thus contributes 2 million deaths annually associated with diarrheal diseases [6]. Perhaps water is the most common potential source of infectious disease as well as chemically induced intoxication and this is why a single source often serves a large number of people thus why water quality is, therefore, the most important only factor to ensure public health [7]. Some waterborne diseases may cause cognitive impairment and growth stunting among children and infant under the age of five [8]. Waterborne diseases are transmitted via pathogen-containing contaminated non-potable water. Different types of diarrheal diseases account for almost $3.6 \%$ of all global burdened disease, which reveals the importance of water potability [9] [10]. Though emerging contaminants are ubiquitous in the aquatic environment, mainly these contaminants are derived from the discharge of municipal wastewater effluents. The existence of these contaminants is of great concern due to the possible ecological impact (e.g., endocrine disruption) to biota within the environment [11].

Water obtained from different sources is associated with a large number of impurities [12]. To make water usable and potable it is necessary to treat water to remove both chemical and biological contaminant. The World Health Organization (WHO) recognizes some issue on water purification that is normally called a point of use for water treatment (PoUWT). These technologies are beneficial for improving water quality in general [13].

Almost a dozen of Vibrio species is responsible for human illness commonly known as vibriosis-three most predominant species include Vibrio parahaemolyticus, Vibrio vulnificus, and Vibrio alginolyticus. A statistics from the Centers for Disease Control and Prevention (CDC) explains that vibriosis is responsible for 80,000 illnesses each year only in the USA. About 52,000 from 80,000 of 
these illnesses are caused by by consuming contaminated food and water [14]. The most common waterborne disease-causing Vibrio is Vibrio cholera. It causes cholera, is an acute diarrheal illness of the intestine. Cholera is prevalent in Indian sub-continent which is transmitted through fecally contaminated water. Water becomes contaminated by releasing untreated sewage water into the river and supply water [15].

Coliform bacteria are a set of merely harmless microbes that mainly found in intestines of warm-blooded animals as normal flora. Fecal coliform is a subgroup of total coliform that is distinct by their capability of growing at elevated temperature. This subgroup is only associated with the fecal substance of warm-blooded animals. Fecal coliform itself is not a pathogenic organism, but it indicates the presence of a pathogenic microorganism [16].

Total coliform bacteria are a collection of comparatively innocuous microorganisms that live in sufficient numbers in the intestines of man, warm and cold-blooded animals. They have a great role in the digestion of food. A specific subgroup of these genera is the fecal coliform bacteria; the most common and foremost member of this group is $E$. coli. Every species of this genre is not harmful. Some strains of $E$. coli are responsible for intestinal illness, E. coli O157:H7 is one of them, which cause intestinal disease. Fecal coliform bacteria have a great significance in indicating sewage contamination of a waterway that indicates the possible presence of other pathogenic microbes [17].

Chlorination is a widely used disinfectant for water purification. But long-term and acute exposure of hypochlorous acid or calcium hypochlorite has an adverse effect in a mammal and the human body. Long-term exposure may cause depression in liver, brain, heart. Decreasing in salivary gland and kidney has also noticed in the in-vitro experiment [18] [19]. Reproductive effects, embryo-toxicity, teratogenicity, mutagenicity, and carcinogenicity have also been noticed in several types of research [20] [21] [22]. Chlorine disinfectant like liquid chlorine, hypochlorous acid, and hypochlorite has adverse effect commonly in children. Irritation of the esophagus, a burning sensation in the mouth and throat, spontaneous vomiting and tissue injury has noticed by sodium hypochlorite and bleach [23].

Assuring the microbiological safety of drinking-water supplies depends on multiple barriers and its use, from catchment to consumer, to prevent the contamination of supplies water or to reduce contamination in a level that is safe for health. The followed strategy is an emphasis on preventing, reducing or blocking the entry of pathogens into water sources and decreasing reliance on water treatment processes for the absence of pathogens [24].

The health concerns associated with chemical contaminants and constituents of drinking-water is slightly different from those related to microbial contamination. Chemical pollutants arise primarily from the ability of chemical components to cause adverse health effects for the consumer after prolonged periods of exposure. Many chemicals may occur in drinking-water; however, only a few are of immediate health concern in any given circumstance. Outbreaks of water- 
borne disease may affect a large number of persons, community or even a particular geographic region. The priority in developing and applying controls on drinking-water quality or water potability should be the control of such outbreaks which cause damage. Some well-known pathogens that are transmitted through the contaminated drinking-water lead to severe and sometimes the life-threatening disease is now limpid to the scientists [25].

\section{Materials and Methods}

\subsection{Sample Collection and Preservation}

Samples were collected from 11 points of different place around Dhaka city, which is shown in Figure 1 and the locations were chosen randomly. Sample water was collected from pipe water which was made by steel. It was an aseptic

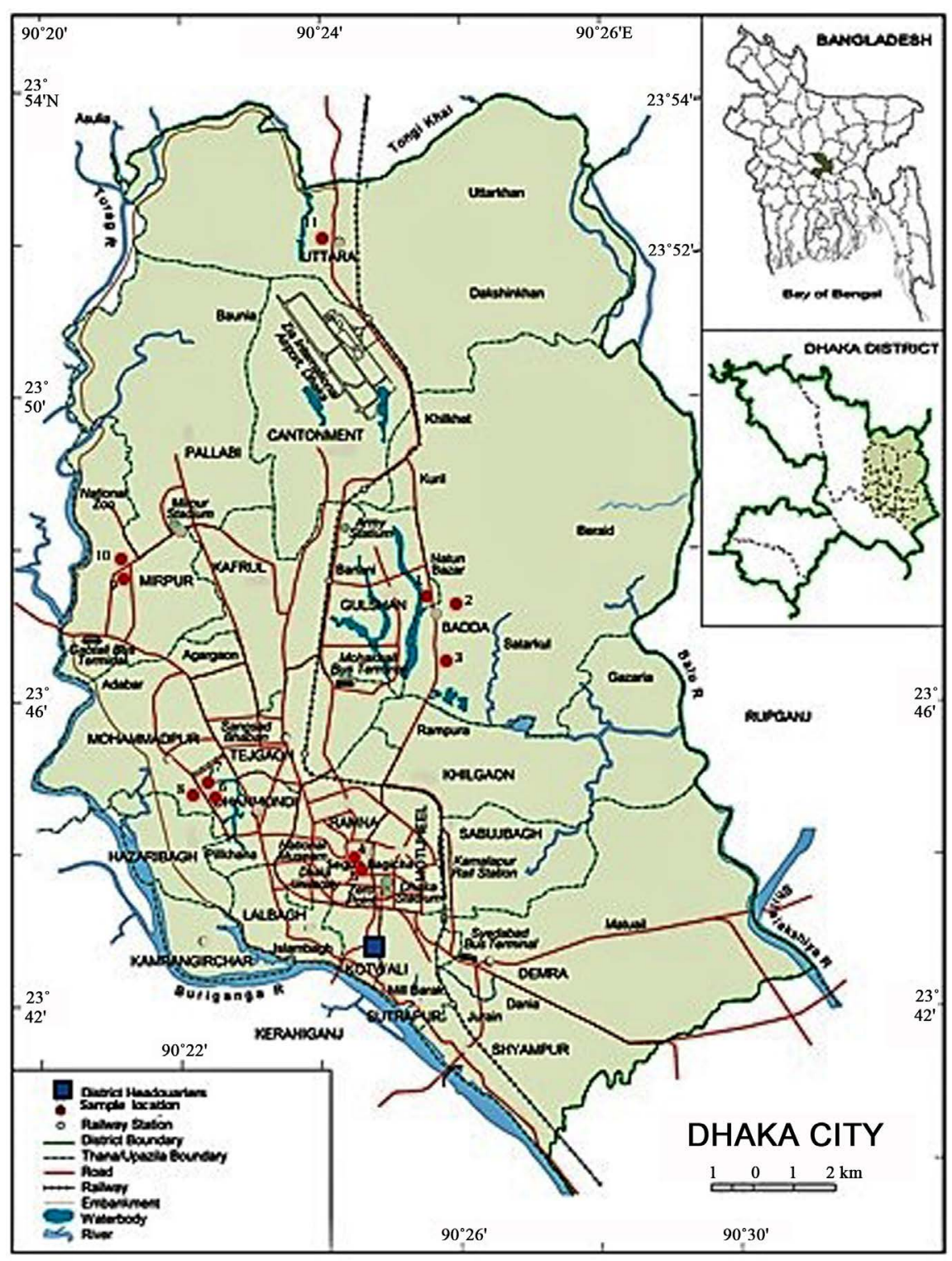

Figure 1. Sample collection sites marked by red colour. 
process where two specimens had collected, one for microbiological test and another one for chemical test. Before the microbial test, samples were preserved at $0^{\circ} \mathrm{C}$. Chemical test performed before microbiological test. Quantification for each experiment had done as per specific validated testing SOP. ISO 19458:2006 is a complete guideline for microbiological analysis on planning water sampling regimes, on sampling procedures and transport, handling, and storage of samples until analysis begins. ISO 19458:2006 focuses on sampling for microbiological investigations. Samples were transported on ice to the laboratory for analysis within three $\mathrm{h}$ of collection. Then the samples were delivered to the laboratory by ISO 5667-1, ISO 5667-2, and ISO 5667-3.

\subsection{Physico-Chemical Properties Determination}

\section{1) Determination of $\mathrm{pH}$}

$\mathrm{pH}$ was measured using a digital meter (Fisher Scientific-AP71; Accuracy- $\pm 0.01 ; \mathrm{mV}$ Accuracy- \pm 0.2 ) according to SOP (APHA standard method for examination of water and waste water $-20^{\text {th }}$ edition).

\section{2) Determination of Chlorine}

Residual and total chlorine was measured by a calibrated HACH DR-900 colorimeter and instrument test kits are based on the DR900 Multi-Parameter Handheld Colorimeter. The range of the meter was $0-4 \mathrm{mg} / \mathrm{L}$, equivalent to 0 $4 \mathrm{ppm}$. The standard operating procedure was based on the APHA Method 4500-CL: Standard Methods for the Examination of Water and Wastewater.

\section{3) Determination of Iron}

Total iron of the water was measured by a calibrated LaMotte Iron Octa-slide 2 comparator and kits under the instruction guide. Sensitivity of the device was 0.5, 1.0, 2.0, 3.0, 4.0, 6.0, 8.0, 10.0 ppm Fe.

\section{4) Determination of Hardness}

Total Hardness (TD) was measured using the Direct Reading Titrator Method by a calibrated LaMotte Total Hardness Direct Reading Titrator-4824 DR-LT-01. The range was 0 - $10 \mathrm{ppm}$, and sensitivity was $0.2 \mathrm{ppm} \mathrm{CaCO}_{3}$.

5) Determination of "TDS"

A calibrated OMEGA conductivity measured TDS, and TDS meter, model-YK-43CD had two distinct ranges of $1.999 \mathrm{mS}$ and $19.99 \mathrm{mS}$ where the accuracy was $\pm(3 \%$ F.S $+1 \mathrm{~d})$.

6) Determination of total alkalinity

A phenolphthalein indicator was added to the sample. Then, the sample was titrated with a sulfuric acid solution. The phenolphthalein indicator changes color at the endpoint $\mathrm{pH}$ of 8.3. This value indicates the phenolphthalein (P) alkalinity and is a measure of the total hydroxide and one-half of the carbonate in the sample. A bromcresol green-methyl red indicator was added, and the titration continues to the second endpoint at a $\mathrm{pH}$ between 4.3 and 4.9. This value indicates the total alkalinity and is a measure of all carbonate, bicarbonate, and hydroxide in the sample. The endpoint $\mathrm{pH}$ is determined with color indicators and with a pH meter. (Ref: HACH-DOC316.53.01151) 


\subsection{Microbiological Properties Determination}

\section{1) Media preparation}

Nutrient agar (NA) was used for the total aerobic count. Violet Red Bile Agar (VRBA) was used for coliform and E. coli. Fecal coliform was isolated by fecal membrane coliform (m-FC) agar with $1 \%$ rosolic acid. Thiosulfate-citrate-bile salts-sucrose agar (TCBS) was used for Vibrio spp. (Figure 2). All media were prepared under ISO 11133:2014 guidelines.

\section{2) Total aerobic count}

Serial dilution was performed up to $10^{-5}$ dilution. Then, $1 \mathrm{ml}$ of each diluent was filtered within $0.45-\mu \mathrm{m}$ membrane filtration by MF-Millipore Membrane Filter, mixed cellulose esters. Then filter paper was transferred and put on a solidified nutrient agar plate. All APC plate was then incubated in an incubator at $32^{\circ} \mathrm{C}$ for 48 hours. This procedure was persuaded through ISO 6222:1999 (Water quality-Enumeration of culturable micro-organisms-Colony count by inoculation in a nutrient agar culture medium).

3) Total coliform and E. coli

$100 \mathrm{ml}$ of the sample was filtered through membranes which retain the bacteria. One membrane (Standard Test) is placed on a selective lactose agar medium (VRBA) which was incubated at $36^{\circ} \mathrm{C}$ for $21 \mathrm{~h}$ and one membrane (Rapid Test) on a case in (tryptic digest)-containing agar medium was incubated at $36^{\circ} \mathrm{C}$ for 4 $\mathrm{h}$ to $5 \mathrm{~h}$, followed by incubation at $44.0^{\circ} \mathrm{C}$ for $19 \mathrm{~h}$ to $20 \mathrm{~h}$ on an agar medium containing casein (tryptic digest) and bile salts. (ISO Standard 9308-1:2000E)

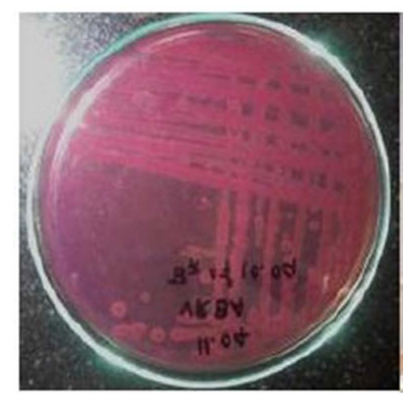

(a)

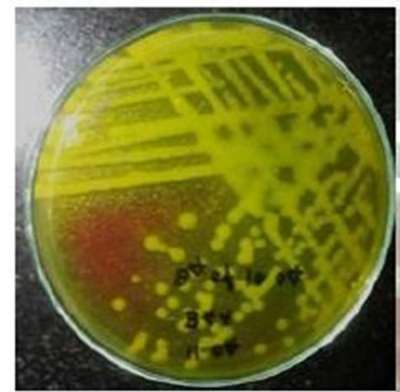

(c)

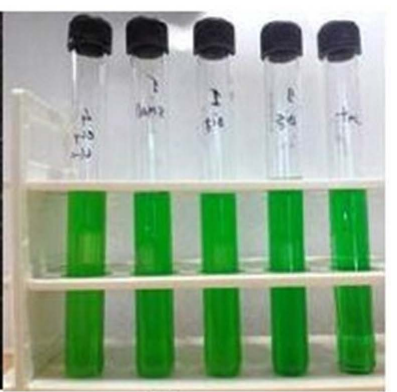

(b)

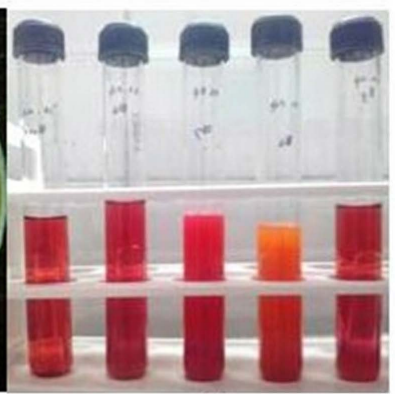

(d)

Figure 2. Coliform and fecal coliform confirmation test: (a) presumptive coliform colony streaked on VRBA; (b) Lactose-fermenting test of positive coliform by BGB; (c) presumptive fecal coliforms colony streaked on BGA; (d) Positive fecal coliform test in MB. 
The individual colonies on the membrane were counted as lactose-positive bacteria. For coliform bacteria and E. coli, subculture was carried out of randomly selected characteristic colonies for confirmatory tests: oxidase and indole production. The numbers of lactose-positive coliform bacteria and E. coli likely to be present in $100 \mathrm{ml}$ of the sample were counted (Standard Test). The colonies on the membrane which were able to form indole from the tryptophan supplied in the agar medium were counted as E. coli. The numbers of $E$. coli likely to be present in $100 \mathrm{ml}$ of the sample were counted (Rapid Test). Colonies giving a negative oxidase reaction was counted as coliform bacteria and colonies giving a negative oxidase, and a positive indole reaction was counted as E. coli. Positive and negative controls were also inoculated where reference organism was used as positive control (Figure 3).

\section{4) Fecal coliform}

Geldreich et al. formulated a medium to enumerate fecal coliforms (m-FC with $1 \%$ Rosolic Acid) using the membrane filter (MF) technique without prior enrichment [26]. Fecal coliforms, which are found in the gastrointestinal tracts and feces of warm-blooded animals, are differentiated from coliforms from environmental sources by their ability to grow at elevated temperatures $44.5^{\circ} \mathrm{C} \pm$ $0.5^{\circ} \mathrm{C}$. Specimens were filtered through separate membrane filters. The membrane was transferred onto the solidified $\mathrm{m}$-FC agar medium. Plates were placed into separate waterproof plastic bags and seal bags to prevent leakage. Plates

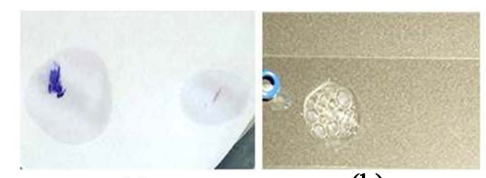

(a)

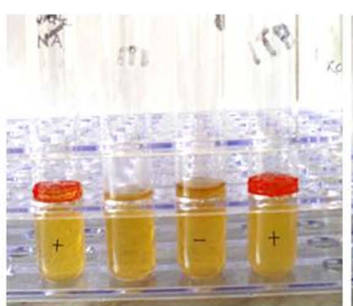

(e)

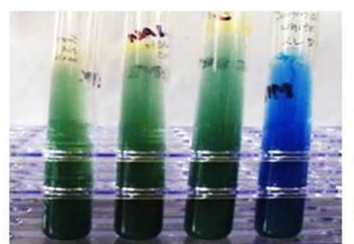

(h)

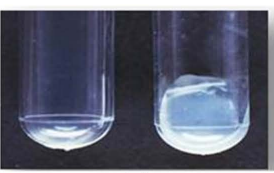

(c)

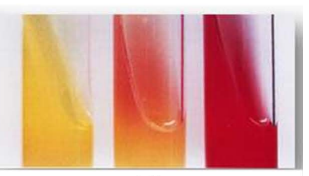

(d)

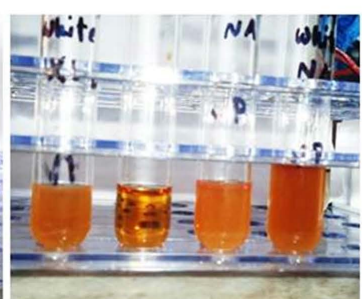

(g)

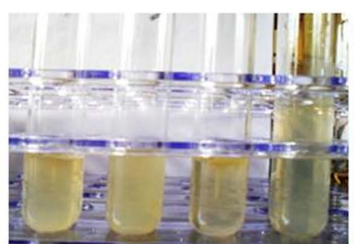

(i)

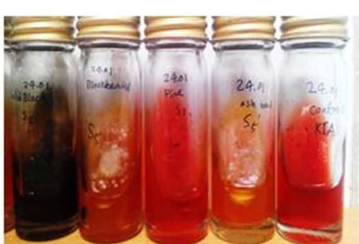

(j)

Figure 3. Different Biochemical confirmation test: (a) positive and negative oxidase test; (b) bubble formation indicate positive catalase reaction; (c) coagulase test; (d) red coloration, positive result for urease; (e) red ring formation, positive indole test; (f) distinct red color, positive MR test; (g) pink red color formation is VP positive result; (h) color change to blue is citrate positive; (i) in motility test, clear test tube indicate non motile and turbid one is motile; ( $\mathrm{j}$ ) which media turn into black is $\mathrm{H}_{2} \mathrm{~S}$ positive. 
were incubated, by immersion, in two different water baths: one was set at $35^{\circ} \mathrm{C}$, and another was at $44.5^{\circ} \mathrm{C}$. Positive and negative controls were also inoculated where reference organism was used as positive control. Typical blue colonies were counted as presumptive fecal coliform (Figure 4).

\section{5) Vibrio spp.}

Vibrio count was done using the membrane filtration method. Briefly, $100 \mathrm{ml}$ of sample was filtered through a $0.45 \mu \mathrm{m}$ size membrane filters under vacuum. The membrane filter was then transferred onto thiosulphate citrate bile salts sucrose (TCBS) agar plates and incubated at $37^{\circ} \mathrm{C}$ for up to $48 \mathrm{~h}$. At the end of the incubation period, typical yellow and green colonies were counted as presumptive Vibrio species and expressed as colony forming units per $100 \mathrm{~mL}$ (CFU/100 $\mathrm{mL})$. Five to ten isolated colonies per plate were then randomly picked and subsequently sub-cultured on sterile TCBS agar plates for purity. Pure isolates were then plated on nutrient agar plates, incubated overnight as ISO/TS 21872-1:2007 [27]. Positive and negative controls were also inoculated. Biochemical identification was done for confirmation according to SOP (Table 1).

\section{Result and Discussion}

The organoleptic observations of water sample give some external idea like color, taste, and odor. All water samples were colorless, tasteless and odorless. Most of the water sample was neutral in $\mathrm{pH}^{\prime}$ but some were slightly acidic or alkaline. According to the Bangladesh water pollution control board [28] [29]; the recommended standard value of $\mathrm{pH}$ range is 6.5 to 9.2 for potable water. All water samples were within the standard limit, and $100 \%$ sample is satisfactory according to $\mathrm{pH}$ standard (Table 2).

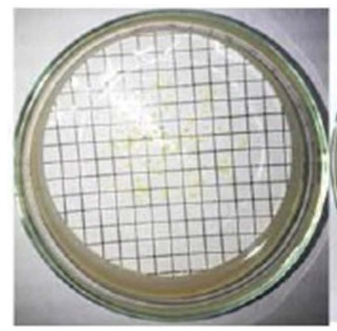

(a)

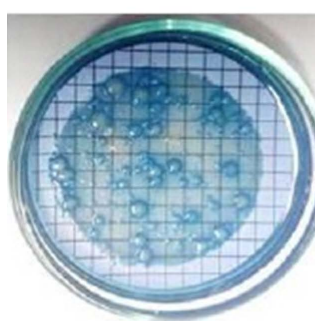

(d)

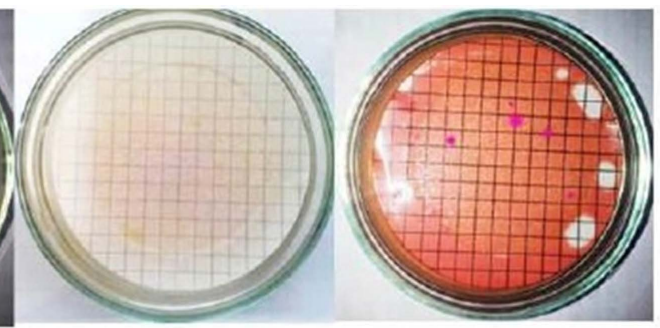

(b)

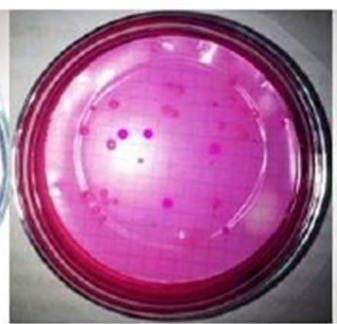

(e) (c)

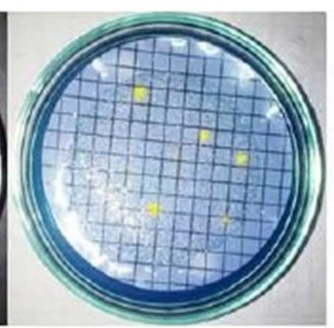

(f)

Figure 4. Presumptive colony of different microorganisms: (a) \& (b)-Total Aerobic count on NA; (c) Colifom on VRBA; (d) Fecal coliform on m-FC agar; (e) E. coli on BRBA; (f) Vibrio spp. on TCBS. 
Table 1. Biochemical characterization.

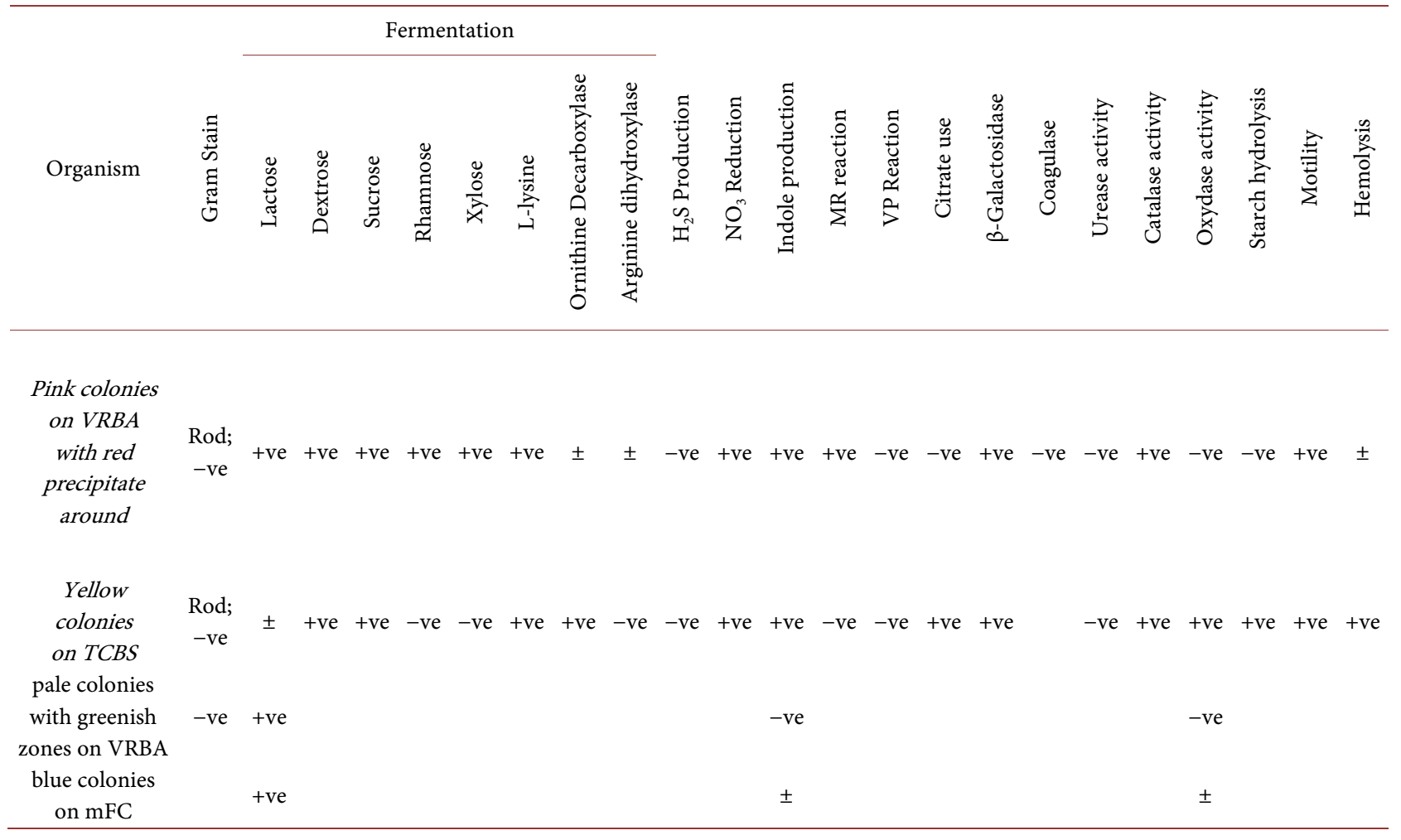

(+ve) means positive result, (-ve) means negative result.

Table 2. Mean microbial count express as the $\log _{10}$ value of different water samples.

\begin{tabular}{lcccccc}
\hline Sample water & $\begin{array}{c}\text { Number of } \\
\text { tested sample }\end{array}$ & $\begin{array}{c}\text { Total aerobic } \\
\text { count }(\mathrm{CFU} / \mathrm{ml})\end{array}$ & $\begin{array}{c}\text { Total coliform } \\
(\mathrm{CFU} / 100 \mathrm{ml})\end{array}$ & $\begin{array}{c}\text { E. coli } \\
(\mathrm{CFU} / 100 \mathrm{ml})\end{array}$ & $\begin{array}{c}\text { Fecal coliform } \\
(\mathrm{CFU} / 100 \mathrm{ml})\end{array}$ & $\begin{array}{c}\text { Vibrio spp. } \\
(\mathrm{CFU} / 100 \mathrm{ml})\end{array}$ \\
\hline Collection point-1 & 7 & $5.27 \pm 2.64$ & $2.35 \pm 0.78$ & $2.16 \pm 0.64$ & $1.32 \pm 0.58$ & $0.68 \pm 0.28$ \\
Collection point-2 & 9 & $4.26 \pm 2.76$ & $1.97 \pm 0.68$ & $1.56 \pm 0.83$ & $0.71 \pm 0.26$ & $\mathrm{Nil}$ \\
Collection point-3 & 7 & $5.54 \pm 3.01$ & $2.67 \pm 1.38$ & $2.24 \pm 0.96$ & $1.46 \pm 0.84$ & $0.77 \pm 0.34$ \\
Collection point-4 & 8 & $5.03 \pm 2.62$ & $2.16 \pm 1.31$ & $2.03 \pm 1.24$ & $1.52 \pm 0.91$ & $0.52 \pm 0.32$ \\
Collection point-5 & 6 & $4.70 \pm 2.70$ & $1.92 \pm 0.73$ & $1.61 \pm 0.64$ & $1.28 \pm 0.52$ & $0.46 \pm 0.24$ \\
Collection point-6 & 7 & $4.32 \pm 2.89$ & $2.03 \pm 1.26$ & $1.63 \pm 0.78$ & $1.36 \pm 0.48$ & $0.32 \pm 0.14$ \\
Collection point-7 & 7 & $6.62 \pm 3.10$ & $3.04 \pm 2.13$ & $2.72 \pm 1.31$ & $2.12 \pm 0.95$ & $0.94 \pm 0.37$ \\
Collection point-8 & 8 & $5.62 \pm 3.23$ & $2.74 \pm 1.57$ & $2.38 \pm 1.07$ & $1.98 \pm 0.86$ & $0.76 \pm 0.36$ \\
Collection point-9 & 6 & $3.47 \pm 1.64$ & $0.82 \pm 0.08$ & $0.53 \pm 0.08$ & $0.48 \pm 0.13$ & $\mathrm{Nil}$ \\
Collection point-10 & 7 & $6.41 \pm 3.85$ & $2.96 \pm 1.89$ & $2.49 \pm 1.14$ & $1.54 \pm 0.43$ & $1.02 \pm 0.46$ \\
Collection point-11 & 8 & $4.28 \pm 2.21$ & $1.82 \pm 1.24$ & $1.58 \pm 0.68$ & $0.58 \pm 0.16$ & $\mathrm{Nil}$ \\
\hline
\end{tabular}

Results are prepared as reproducibility and shown with standard deviation.

In Table 2, TDS of the collected samples were not within the limit for every sample, where the standard TDS is set up 500 ppm by USEPA. $28.75 \%$ sample was above the standard limit where lowest count was $169.2 \mathrm{ppm}$, and the highest 
count was $593.6 \mathrm{ppm}$.

General guidelines for classification of waters by USEPA, according to USEPA hardness are: 0 to $60 \mathrm{mg} / \mathrm{L}$ (milligrams per liter) as calcium carbonate is classified as soft; 61 to $120 \mathrm{mg} / \mathrm{L}$ as moderately hard; 121 to $180 \mathrm{mg} / \mathrm{L}$ as hard; and more than $180 \mathrm{mg} / \mathrm{L}$ as very hard. According to the standard guideline, the most water sample is moderately soft. Unsatisfactory for hardness guideline is only $15 \%$ according to the standard guideline (Table 2). Alkalinity standard is 500 ppm of carbonate along with TDS according to USEPA. A tested water sample is within the standard limit because dissolved cation is moderately low in amount. The unsatisfactory percentage is very narrow which is only $3.75 \%$ has been shown in the same table.

Chlorine standard set up by the WHO [25] as a residual concentration of free chlorine of greater than or equal to $0.5 \mathrm{ppm}$ after at least 30 minutes of contact time at $\mathrm{pH}$ less than 8.0. This is the most concerning physicochemical parameter. According to criterion, only $46.25 \%$ sample is within the limit. $53.75 \%$ sample was unsatisfactory for chlorine presence (Figure 5). Total chlorine was present in a range of 0.83 to 12.56 . Whole 43 samples out of 80 samples were above the standard limit (Table 2).

According to the USEPA standard level of iron in potable drinking water is $<0.3 \mathrm{mg} / \mathrm{L}$. Customarily ground water contains more iron then surface water [12]. The iron level of the collected sample is $91.25 \%$, which is within the standard and tolerate limit (Table 2).

The microbiological standard of water depends on various extrinsic and intrinsic factors. Usually, raw wastewater contains more micro-flora because the presence of different organic and inorganic nutrients and Higher BOD [30] but groundwater is initially free of these contaminants, and so, groundwater has lower microorganisms. In general, the greatest microbial risks are associated with ingestion of water that is contaminated with human or animal (including

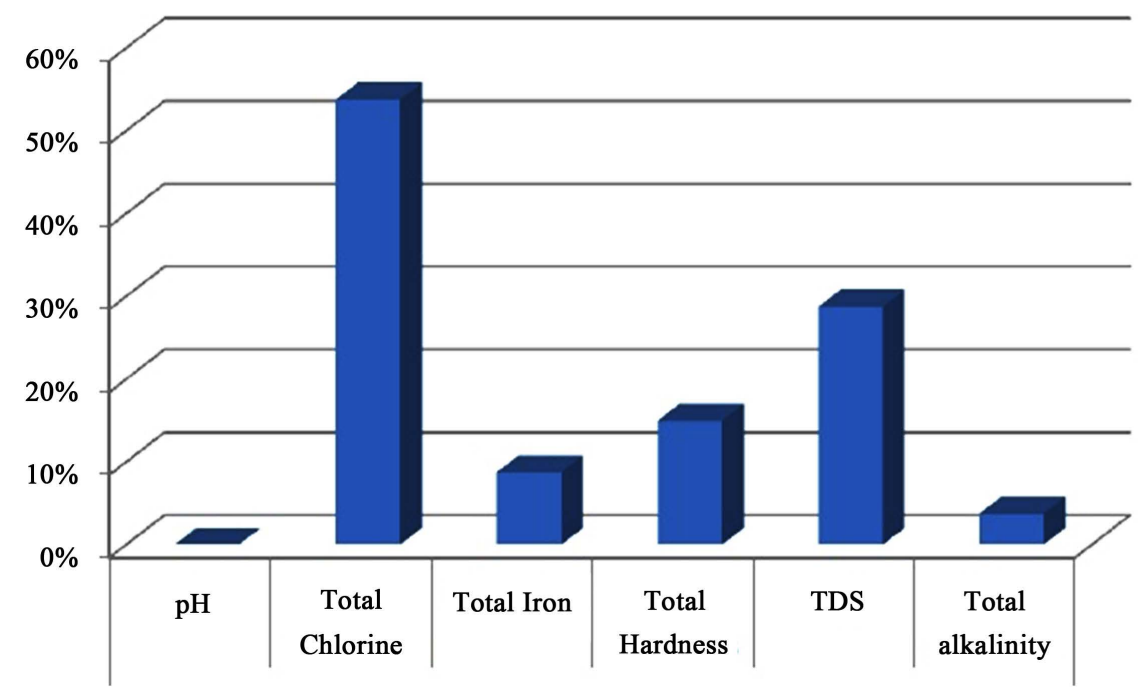

Figure 5. Unsatisfactory rate according to microbiological parameters. 
bird) faces. Faces can be a source of pathogenic bacteria, viruses, protozoa, and helminths [31].

Total five microbiological parameters have been tested for all collected water samples. The total aerobic count is high for tested water. The standard total aerobic count is less than $1.0 \times 10^{3} / \mathrm{ml}$ for drinking water (ISO BDS 1240:2001) (ESEPA < 500). According to standard, 43 samples were out of limit that is $53.75 \%$ of the total samples and the range was $0.60 \times 10^{2}$ to $7.34 \times 10^{8} \mathrm{CFU}$. Total coliform is an indication of water pathogenic contamination. According to WHO, the limit of coliform is zero for $100 \mathrm{ml}$ of water for the membrane filtration technique. But $76.25 \%$ water sample had coliform contamination. From 80 samples, 61 samples were coliform contaminated. The lowest value of coliform was 0 , and the highest value was $4.82 \times 10^{4} \mathrm{CFU}$ in $100 \mathrm{ml}$ of water. E. coli is another indicator organism which standard limit is zero per $100 \mathrm{ml}$ of water set up by USEPA (2014) and no/250 $\mathrm{ml}$ by EU. $61.25 \%$ water sample contains $E$. coli that mean 49 collected samples is unsatisfactory according to the criterion. $E$. coli was present at a range of 0 to $2.37 \times 10^{3} \mathrm{CFU} / 100 \mathrm{ml}$ (Table 3 ).

Fecal coliform is an indicator for fecal contamination of the sample. Sample water has more fecal coliform than standard limit. According to WHO, there should not be any fecal coliform in potable drinking water. Despite this, our collected samples have a range of 0 to $4.18 \times 10^{3} \mathrm{CFU}$ fecal coliform, which is not acceptable. Forty-seven samples are unsatisfactory for this parameter that is $58.75 \%$ of the total sample (Figure 6). One of the halophilic microorganism is Vibrio spp. The Vibrio genus has been one of the major pathogens known to cause outbreaks worldwide, but mostly known for creating cholera [27] [32]. According to FDA, the presence of Vibrio spp. is vulnerable. On this aspect, $13.75 \%$ sample is not satisfactory because of this water contains Vibrio. 11 samples out of 80 were Vibrio contaminated (Table 3 ).

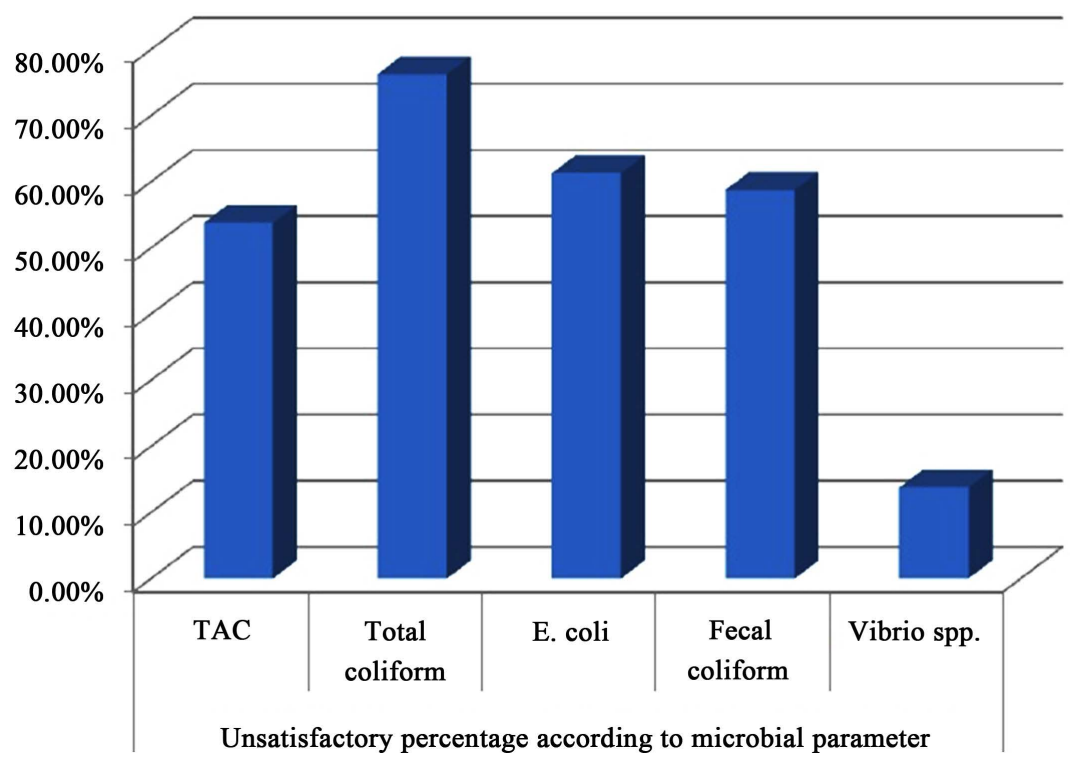

Figure 6. Unsatisfactory rate according to physic-chemical parameters. 
Table 3. Physico-chemical parameters of different water samples.

\begin{tabular}{cccccccc}
\hline Sample water & $\begin{array}{c}\text { Number of } \\
\text { tested sample }\end{array}$ & $\mathrm{p}^{\mathrm{H}}$ & $\begin{array}{c}\text { Total Chlorine } \\
(\mathrm{PPM})\end{array}$ & $\begin{array}{c}\text { Total Iron } \\
(\mathrm{mg} / \mathrm{L})\end{array}$ & $\begin{array}{c}\text { Total Hardness } \\
(\mathrm{mg} / \mathrm{L})\end{array}$ & $\begin{array}{c}\text { TDS } \\
(\mathrm{PPM})\end{array}$ & $\begin{array}{c}\text { Total alkalinity } \\
(\mathrm{PPM} \text { as CaCO }\end{array}$ \\
\hline Collection point-1 & 7 & $6.89 \pm 0.13 \mathrm{a}$ & $4.28 \pm 0.36 \mathrm{a}$ & $0.12 \pm 0.016 \mathrm{a}$ & $107.2 \pm 8.2 \mathrm{a}$ & $356.7 \pm 23.6 \mathrm{a}$ & $78.2 \pm 8.3 \mathrm{a}$ \\
Collection point-2 & 9 & $7.16 \pm 0.21 \mathrm{~b}$ & $5.89 \pm 0.94 \mathrm{~b}$ & $0.093 \pm 0.011 \mathrm{~b}$ & $142.7 \pm 13.5 \mathrm{~b}$ & $453.6 \pm 33.8 \mathrm{~b}$ & $96.4 \pm 13.2 \mathrm{~b}$ \\
Collection point-3 & 7 & $7.21 \pm 0.16 \mathrm{bc}$ & $6.73 \pm 1.06 \mathrm{c}$ & $0.18 \pm 0.021 \mathrm{c}$ & $96.4 \pm 7.4 \mathrm{c}$ & $237.1 \pm 21.3 \mathrm{c}$ & $68.4 \pm 7.1 \mathrm{c}$ \\
Collection point-4 & 8 & $7.06 \pm 0.09 \mathrm{~d}$ & $3.62 \pm 0.42 \mathrm{~d}$ & $0.17 \pm 0.014 \mathrm{~cd}$ & $98.7 \pm 7.9 \mathrm{~cd}$ & $517.2 \pm 76.4 \mathrm{~d}$ & $67.6 \pm 4.9 \mathrm{~cd}$ \\
Collection point-5 & 6 & $7.14 \pm 0.17 \mathrm{bce}$ & $2.84 \pm 0.73 \mathrm{e}$ & $0.087 \pm 0.009 \mathrm{e}$ & $126.1 \pm 18.2 \mathrm{e}$ & $342.1 \pm 42.2 \mathrm{e}$ & $85.2 \pm 7.2 \mathrm{e}$ \\
Collection point-6 & 7 & $6.96 \pm 0.18 \mathrm{af}$ & $3.82 \pm 0.76 \mathrm{df}$ & $0.16 \pm 0.013 \mathrm{cdf}$ & $85.2 \pm 6.7 \mathrm{f}$ & $305.3 \pm 31.7 \mathrm{f}$ & $81.3 \pm 5.2 \mathrm{f}$ \\
Collection point-7 & 7 & $7.08 \pm 0.16 \mathrm{dg}$ & $5.62 \pm 0.91 \mathrm{~g}$ & $0.15 \pm 0.012 \mathrm{acdg}$ & $88.1 \pm 7.27 \mathrm{~g}$ & $267.2 \pm 24.4 \mathrm{~g}$ & $78.1 \pm 6.8 \mathrm{ag}$ \\
Collection point-8 & 8 & $7.31 \pm 0.20 \mathrm{~h}$ & $6.12 \pm 0.83 \mathrm{bh}$ & $0.092 \pm 0.008 \mathrm{bh}$ & $106.3 \pm 14.9 \mathrm{ah}$ & $196.8 \pm 27.6 \mathrm{~h}$ & $61.2 \pm 6.5 \mathrm{~h}$ \\
Collection point-9 & 6 & $6.93 \pm 0.07 \mathrm{afi}$ & $8.16 \pm 3.37 \mathrm{i}$ & $0.18 \pm 0.017 \mathrm{cdfgi}$ & $90.7 \pm 6.81 \mathrm{i}$ & $356.1 \pm 34.7 \mathrm{ai}$ & $94.1 \pm 11.3 \mathrm{i}$ \\
Collection point-10 & 7 & $7.43 \pm 0.15 \mathrm{j}$ & $4.73 \pm 0.65 \mathrm{j}$ & $0.16 \pm 0.020 \mathrm{cdfgj}$ & $97.8 \pm 7.42 \mathrm{cdj}$ & $416.2 \pm 23.8 \mathrm{j}$ & $69.8 \pm 7.8 \mathrm{cdj}$ \\
Collection point-11 & 8 & $7.26 \pm 0.21 \mathrm{ck}$ & $7.38 \pm 1.17 \mathrm{k}$ & $0.19 \pm 0.018 \mathrm{ik}$ & $106.4 \pm 11.3 \mathrm{ak}$ & $338.2 \pm 42.6 \mathrm{ek}$ & $74.8 \pm 8.6 \mathrm{k}$ \\
\hline
\end{tabular}

Results are prepared as repeatability and shown with standard deviation. Means sharing a common letter do not differ significantly, others differ significantly $(\mathrm{p}<0.05)$.

Both microbial and physicochemical properties depend on sampling time. Different properties of water change season to the season [27]. In rainy season surface water become dilute and become dense in winter, so different anion, cation, organic substance may vary in a different season. The microbial count is also related to this seasoning because different nutrient and growth factors also get changed from time to time [33].

The contact (retention) time in chlorination is that period between the introduction of the disinfectant and when the water is used. A long interaction between chlorine and the microorganisms results in an effective disinfection process (USEPA). Chlorine level is essential for microbial lessening but over the amount of chlorine is harmful to the consumer. So, an optimum level of chlorine dosing is essential for both points of view. Nearly every day a new chemical, toxin, pharmaceutical drug, radioactive residue or parasite is contaminating our water supply, and especially our drinking water [34]. According to a working group study, $85 \%$ U.S. population's water is laced with over 300 contaminants but purifying chlorine substances causing most harm of all. Some ways chlorine in our drinking is harming our health [35].

The first way of damaging our health is killing good gut bacteria. Chlorine worked as a disinfectant and wiped out beneficial bacteria like lactobacilli. Improper chlorine dosing causes the resistance of pathogenic bacteria and parasites. The second harmful effect of chlorine is chlorine acts as an estrogen mimic. When chlorine absorbed by the body, chlorine becomes $\mathrm{x}$ enoestrogens which can result in cancer and many other health concerns like hair loss, fatigue, lack of libido, hypothyroidism, hypoglycemia, insomnia. Chlorine also hurts weight gaining. As a toxic chemical, chlorine displaces the iodine in thyroid leading to hypothyroidism and unwanted side effects like weight gain and hot flashes [36]. Chlorine also creates a problem by producing trihalomethanes (THMs) and ha- 
loacetic acids when it reacts with water's natural organic compounds.

Waterborne diseases are caused by pathogenic microorganisms found in water. Pathogen contaminated water may cause illness while bathing, washing or drinking. Diarrheal diseases are a most prominent example because it causes 842,000 deaths every year [37]. The disease-causing microorganism is mainly protozoa and bacteria. When a water sample contains coliform or fecal coliform, it indicates the presence of other pathogenic organisms. Drinking water contaminated with Vibrio cholera cause cholera. In severe forms, cholera is known to be one of the most rapidly fatal illnesses. Every E. coli bacterium is not pathogenic but some strain like O157:H7 is responsible for severe bloody diarrhea and abdominal cramps. The hemolytic uremic syndrome is also found in children (Source: Centers for Disease Control and Prevention, Preventing Foodborne Illness: Escherichia coli O157:H7, 1993). Presence of fecal coliform in water is a presage of dysentery-causing pathogens like Salmonella or Shigella. Salmonella is also responsible for salmonellosis and typhoid fever [38].

We had some technical lacking in our laboratory. Some common chemical parameters like $\mathrm{NH}_{4}^{+}, \mathrm{NO}_{2}^{-}, \mathrm{NO}_{3}^{-}$, and $\mathrm{PO}_{4}^{3-}$ cannot be determined. More sampling site would give more authenticity. Nowadays molecular identification is very common, but we had to rely on a cultural and biochemical test for detection of E. coli and Vibrio spp.

In the future there are different scopes for research on water treatment, which can be accomplished. Concentrations of an antimicrobial agent, heavy metal, toxic and carcinogenic substances are also some vulnerable parameters. Which chemical compound is a microbial indicator of contamination can be worked out. Root cause and their remedies is also a great task for future research. Proper monitoring of the treatment process to ensure compliance to set guidelines is highly recommended. Advanced technology should evolve for recycling and reuse of water. High-pressure membrane filtration, ultra violate irradiation, reverse osmosis, ion exchange technology may involve for water treatment. Consumer education and consciousness are necessary, and unwanted human activity should stop.

\section{Conclusion}

Both chemical and microbial parameter should be the norm of potable water. In this study, the presence of total coliform and other microbial contaminants suggest that supplied water is highly contaminated with pathogens and great reservoirs for them. Even a high dose of chlorination fails to kill bacteria within a safe level, although chlorine is a highly toxic substance and main concern in the chemical parameter. The unsatisfactory percentage of these pathogens also suggests the inefficiency of the water treatment plants to adequately remove microbial pathotypes, which is a threat to public health. Regular and routine monitoring of the treating process to ensure compliance for setting guidelines is the recommendation from here. 


\section{Acknowledgements}

We would like to thank all the anonymous individuals who helped us during our research work and special thanks to Dr. Mahfuzur Rahman, Associate Professor in the department of Environmental Science and Technology.

\section{Conflicts of Interest}

The authors declare they have no competing interest.

\section{References}

[1] UNDP (United Nations Development Programme) (2006) Human Development Reports. Beyond Scarcity: Power, Poverty and the Global Water Crisis.

[2] Clifford Chance LLP Corporate (October 2011) Tackling Water Scarcity. Advocates for International Development.

[3] Ye, Q., Li, Y., Zhuo, L., Zhang, W., Xiong, W., Wang, C. and Wang, P. (2018) Optimal Allocation of Physical Water Resources Integrated with Virtual Water Trade in Water-Scarce Regions: A Case Study for Beijing, China. Water Research, 129, 264-276. https://doi.org/10.1016/j.watres.2017.11.036

[4] McDonald, R.I., Weber, K.F., Padowski, J., Boucher, T. and Shemie, D. (2016) Estimating Watershed Degradation over the Last Century and Its Impact on Water-Treatment Costs for the World's Large Cities. Proceedings of the National Academy of Sciences of the United States of America, 113, 9117-9122. https://doi.org/10.1073/pnas.1605354113

[5] Shevah, Y. (2014) Water Scarcity, Water Reuse, and Environmental Safety. Pure and Applied Chemistry, 86, 1205-1214. https://doi.org/10.1515/pac-2014-0202

[6] WHO (World Health Organization) (2014) UN-Water Global Analysis and Assessment of Sanitation and Drinking Water (GLAAS) 2014-Report, Investing in Water and Sanitation: Increasing Access, Reducing Inequalities.

[7] Madigan, T.M., Martinko, J.M., Bender, S.K., Buckley, D.H. and Stahl, D.A. (2010) Brock Biology of Microorganisms. 13th Edition, Benjamin Cummings, San Francisco, Chapter 35.

[8] Dillingham, R. and Guerrant, R.L. (2004) Childhood Stunting: Measuring and Stemming the Staggering Costs of Inadequate Water and Sanitation. The Lancet, 363, 94-95. https://doi.org/10.1016/S0140-6736(03)15307-X

[9] Murray, C.J., Vos, T., Lozano, R., Naghavi, M., Flaxman, A.D., Michaud, C., et al. (2012) Disability-Adjusted Life Years (DALYs) for 291 Diseases and Injuries in 21 Regions, 1990-2010: A Systematic Analysis for the Global Burden of Disease Study 2010. The Lancet, 380, 2197-2223. https://doi.org/10.1016/S0140-6736(12)61689-4

[10] Clasen, T.F., Alexander, K.T., Sinclair, D., Boisson, S., Peletz, R., Chang, H.H., Major, F. and Cairncross, S. (2015) Interventions to Improve Water Quality for Preventing Diarrhea. Cochrane Database of Systematic Reviews, Issue 10, Art. No.: CD004794.

[11] Bruce, P., Ruth, B. and Barbara, K.H. (2015) A Review on Emerging Contaminants in Wastewaters and the Environment: Current Knowledge, Understudied Areas, and Recommendations for Future Monitoring. Water Research, 72, 3-27. https://doi.org/10.1016/j.watres.2014.08.053

[12] Sharma, B.K. (1994) Environmental Chemistry. 1st Edition, Krishna Prakashan 
Media, Delhi, 9-11.

[13] Ehdaie B., Renton, C.T., Son, V., Turner, S.S., Samie, A., Dillingham, R.A. and Smith, J.A. (2017) Evaluation of a Silver-Embedded Ceramic Tablet as a Primary and Secondary Point-of-Use Water Purification Technology in Limpopo Province, S. Africa. PLoS ONE, 12, e0169502. https://doi.org/10.1371/journal.pone.0169502

[14] CDC (Centers for Disease Control and Prevention) (2017) Vibrio Species Causing Vibriosis.

[15] Global Hydration (2017) Common Waterborne Disease, Bacteria, Viruses and Cysts.

[16] Doyle, M.P. and Erickson, M.C. (2006) Closing the Door on the Fecal Coliform Assay. Microbe, 1, 162-163.

[17] Brian, O. (2014) Fecal Coliform Bacteria in Water. Water Research Center.

[18] IARC (International Agency for Research on Cancer) (1991) Chlorinated Drinking-Water; Chlorination By-Products; Some Other Halogenated Compounds; Cobalt and Cobalt Compounds. International Agency for Research on Cancer, Lyon, 45-359.

[19] IARC (International Agency for Research on Cancer) (1991) IARC Monographs on the Evaluation of Carcinogenic Risks to Humans, Volume 52.

[20] Druckrey, H. (1968) Chlorinated Drinking Water Toxicity Tests Involving Seven Generations of Rats. Food and Cosmetics Toxicology, 6, 147-154. https://doi.org/10.1016/0015-6264(68)90196-X

[21] Meier, J.R. (1985) Evaluation of Chemicals Used for Drinking Water Disinfection for Production of Chromosomal Damage and Sperm-Head Abnormalities in Mice. Environmental Mutagenesis, 7, 201-211. https://doi.org/10.1002/em.2860070208

[22] Kurokawa, Y. (1986) Long-Term in Vivo Carcinogenicity Tests of Potassium Bromate, Sodium Hypochlorite, and Sodium Chlorite Conducted in Japan. Environmental Health Perspectives, 69, 221-235. https://doi.org/10.1289/ehp.8669221

[23] Research Triangle Park, NC, US Department of Health and Human Services (1992) National Toxicology Program. Report on the Toxicology and Carcinogenesis Studies of Chlorinated and Chloraminated Water in F344/N Rats and B6C3F1 Mice.

[24] Smith, J. (2008) Dangers of Chlorine. http://curezone.com/art/read.asp? ID $=21 \& \mathrm{db}=3 \& \mathrm{CO}=7$

[25] WHO (World Health Organization) (2008) Guidelines for Drinking-Water Quality, the Third Edition Incorporating the First and Second Addenda, Volume 1 Recommendations. WHO, Geneva.

[26] Geldreich, E.E., Clark, H.F., Huff, C.B. and Best, L.C. (1965) Fecal Coliform Organism Medium for the Membrane Filter Technique. Journal of the American Water Works Association, 57, 208-214. https://doi.org/10.1002/j.1551-8833.1965.tb01388.x

[27] Nongogo, V., Adefisoye, M., Olayemi, O.O. and Nontongara, N. (2015) Prevalence and Characterization of Non-Cholera Vibrio Spp. in Final Effluent of Wastewater Treatment Facilities in Two Districts of the Eastern Cape Province of South Africa: Implication for Public Health. Environmental Science and Pollution Research, 22, 2008-2017. https://doi.org/10.1007/s11356-014-3461-z

[28] BWPCB (Bangladesh Water Pollution Control Board) (1976) Water Quality Standard.

[29] WHO (World Health Organization) (1967) International for Drinking Water, Palais Des Nations, Geneva.

[30] USEPA (The United States Environmental Protection Agency) (2017) Drinking 
Water Contaminants, Standards, and Regulations.

[31] Andrews, W.A., Moore, D.K. and Leroy, A.C. (1972) A Guide to the Study of Environmental Pollution. Prentice-Hall, Englewood, $250 \mathrm{p}$.

[32] Griffith, D.C., Kelly-Hope, L.A. and Miller, M.A. (2006) Review of Reported Cholera Outbreaks Worldwide, 1995-2005. The American Journal of Tropical Medicine and Hygiene, 75, 973-977. https://doi.org/10.4269/ajtmh.2006.75.973

[33] Bahlaoui, M.A., Baleux, B. and Troussellier, M. (1997) Dynamics of Pollution Indicators and Pathogenic Bacteria in High Rate Oxidation Wastewater Treatment Ponds. Water Research, 31, 574-582.

https://doi.org/10.1016/S0043-1354(96)00299-0

[34] Jon, J. and Calomiris, K.A. (1998) How Does Chlorine Add to Drinking Water Kill Bacteria and Other Harmful Organisms? Why Doesn't It Harm Us?

[35] YHK (2017) 3 Ways Chlorine in Drinking Water Is Harming Your Health.

[36] WHO (World Health Organization) (2014) The Burden of Disease and Cost-Effectiveness Estimates.

[37] Dziuban, E.J., Liang, J.L., Craun, G.F., Hill, V. and Yu, P.A. (2006) Surveillance for Waterborne Disease and Outbreaks Associated with Recreational Water, United States, 2003-2004. MMWR Surveillance Summaries, 55, 1-30.

[38] CDC (Centers for Disease Control and Prevention) (1993) Preventing Foodborne Illness: Escherichia coli O157:H7. 